\title{
Research of the Correlation of Spiritual-Moral and Emotional-Expressional Characteristics of Personality
}

\author{
Milyausha R. Khairutdinova ${ }^{1}$ \\ ${ }^{1}$ Kazan (Volga region) Federal University, Kazan, Russia \\ Correspondence: Regina K. Nabiullina, Kazan (Volga region) Federal University, Kremlyovskaya Street 18, \\ Kazan, 420008, Russia.
}

Received: December 29, 2014

Accepted: January 22, 2015 Online Published: February 11, 2015

doi: $10.5539 /$ res.v7n4p83

URL: http://dx.doi.org/10.5539/res.v7n4p83

\begin{abstract}
The article deals with the problem of spiritual and moral development of the modern human. This process is understood as interiorization by a human of ideal (external) forms of spiritual and moral culture by means of psychological tools (transmitters), the role of which the emotional and expressional characteristics play within the this research. The goal of this research resides in revealing main directions of study of spiritual and moral development of personality, including involvement of the emotional sphere in the formation and development of spiritual and moral personality, as well as determination of singularities of the correlation (contingence) between spiritual-moral and emotional-expressional characteristics of personality based on the materials of students. Theoretical analysis showed that spiritual and moral development of personality is implemented through human's assimilation of ideal forms of spiritual and moral culture by means of psychological tools (transmitters). Based on the analysis of main regulatory functions of psychological tools, it was determined that emotional and expressional characteristics can play important role in assimilation of the spiritual and moral culture, being both the form of its expression and the psychological tools of mastering this culture at the same time. Comparative analysis of the results of the diagnostics of spiritual-moral and emotional-expressional characteristics revealed statistically valid differences. For example, in the female group, the following differences in values were revealed: the anger emotion, excessive motions, peacemaking, general expressivity, loud voice, expression of anger and fear. The male group differed by the following values: egoism, spiritual strength, spiritual beauty, righteousness, soul purity, expression of anger. Comparison of the obtained correlative pleiads describing the spiritual-moral and emotional-expressional level between all groups allowed identifying the following trend: the increase of the general level of humanism and other spiritual and moral indicators of the responders is accompanied by the growth of importance and contingency of the correlation with the emotional and expressional indicators.
\end{abstract}

Keywords: spiritual and moral development of personality, interiorization, exteriorization, emotional and expressional characteristics, psychological tools (transmitters)

\section{Introduction}

The spiritual and moral development of the young generation becomes especially important in the circumstances of the current Russian education, the main task of which is formation and development of the spiritual and moral culture of the modern youth. By now, great experience in the study of the problem of spiritual and moral development of humans has been accumulated (Abolin, 2002; Popov, 2000; Zinchenko, 1994; Znakov, 1998), which is based on the search of mechanisms of formation and conditions of development of the spiritual and moral personality. However, research of the emotional parameters of the spiritual and moral formation of the personality suffers lack of attention. Several researchers (Anisimov, 2001; Berkowitz, 1990; Izard, 1965, 1989, 1990; Malatesta, 1990; Olshannikova, 1974; Wessman \& Ricks, 1966) acknowledged the necessity of proper orientation in emotional phenomena, as they believed it to play a significant role in the moral and spiritual parenting of the modern human. The assumption (Abolin, 2002; Zinchenko, 1994) that the spiritual and moral development of personality is the process of assimilation by a person of the ideal forms of the spiritual and moral culture is quite interesting. By mastering (interiorizing) the ideal form of spiritual culture, a person associates it with himself, and it becomes his own subjectively real one (the individual form). The process of interiorization is often assisted by intermediate transmitters or psychological tools of development, as which researchers treat an 
adult in the process of interindividual activity (Bozhovich, 1977; Vygotsky, 2005), character and word (Elkonin, 1989; Salmina, 1988; Vygotsky, 2005), sense and myth (Vygotsky, 2005). The function of the said transmitters resides in the fact that when being assimilated, they contribute to formation and improvement of new psychological establishments, rebuild them, and organize mutual relationship between them.

Basing on the theoretical provisions, we undertook a research targeting revelation of main directions of the study of spiritual and moral development of personality, including participation of the emotional sphere in the issues of formation and development of spiritual and moral personality. It also targeted determination of singularities of the correlation (contingency) between emotional-expressional and spiritual-moral characteristics of personality. The research stated an assumption that emotional and expressional characteristics can act as psychological tools (transmitters) of assimilation and reproduction by a person of the spiritual and moral experience, which along with the known transmitters act as mechanisms (means) of implementation of the processes of interiorization and exteriorization.

\section{Materials and Methods}

Several techniques were included in the empirical tool set for carrying out the research. In order to evaluate the spiritual and moral singularities of students, the following techniques were used:

- "Good-Evil" (Popov \& Kashin, 2000), which diagnoses two alternative features of personality by the functions of the Good and Evil qualities;

- "Spiritual differential" (Aminev, 1994), which allows to evaluate the spiritual potential of personality by its three values: spiritual power, spiritual beauty as a total of spiritual values, and spiritual activeness;

- "Self and mutual evaluation of the personality spirituality" (Aminev, 1994), which determines the following spiritual and moral singularities: spiritual bluntness, weakness, spiritual lenity, righteousness, mercy, soul purity, peacemaking, honesty, persecution;

- The technique of "Spiritual distortion" (Aminev, 1994), which reveals the most accentuated directions of spiritual distortion such as egoism, spiritual irresponsibility, strive for domination, and generation of evil.

In order to reveal emotional and expressional characteristics of a personality, the following techniques were used:

- "Measurement of singularities of the emotional expression" (Olshannikova \& Rabinovich, 1974), targeting diagnostics of singularities of the following expression channels: general expressiveness, voice volume, speech ratio, figurativeness of speech, grammatical orientation of speech, voice tone, motor activity, excessive moves, mimicry, expression of gladness, expression of anger, expression of fear;

- "The methodology of studying qualitative and modal emotional singularities (Olshannikova \& Rabinovich, 1974), which allows to receive individual estimations by three dominating emotional experiences - gladness, anger, and fear. All diagnostic techniques used in the research are standardized and meet the requirements of validity, reliability, and representativeness. The techniques of the research were presented to the participants individually. All participants of the research who requested it received the results of the psychological diagnosis with its further discussion.

Collection of empirical materials was carried out at the premises of a pedagogical higher educational institution. 234 students - 61 young males and 173 young females - took part in the research. Selection of young males and females as the object of study was determined by the fact that the young generation is the most sensitive group of the population, which needs formation and development of their spiritual and moral culture. The homogeneity of the studied sampling was provided by the similarity of the tested persons by a battery of criteria: age category, ethnicity (approximately equal number of Russians and Tartars), sex, and social status.

The research was carried out in several steps. At the first stage, the tested persons were broken up into three groups according to the Popov's technique (Popov \& Kashin, 2000). These groups were formed according to the values of their righteousness, evil intent, and general humanism (spirituality). Such division was determined by the author's vision of Humanism as the integral indicator of moral development of personality. Increase of the humanism indicators can evidence the process of moral improvement of the personality. The first group consisted of young females with the high value of righteousness and humanism (61 persons), the second-young females with the medium level of the said features ( 87 persons), and the third-young females with the low level of righteousness and humanism ( 25 persons). Similarly, male tested persons were broken up into groups. The results of the sampling were as follows: 23,21 and 17 persons. At the next stage, the individual values describing the spiritual and moral potential and emotional and expressional singularities of students were determined. In 
accordance with the research tasks, all empirical data underwent statistic processing (Statistic comparison of the average values by the $t$-criterion of Student, the correlative analysis). The designations $p<0.05 ; p<0.01 ; p<0.001$ were used for describing the level of statistical significance at displaying the results.

\section{Results}

Comparative analysis of the results of the diagnostics of spiritual-moral and emotional-expressional characteristics revealed statistically valid differences. For example, in the female group, the following differences in values were revealed: the anger emotion, excessive motions, peacemaking, general expressivity, loud voice, expression of anger and fear. The male group differed in the following values: egoism, spiritual strength, spiritual beauty, righteousness, soul purity, expression of anger.

The singularities of the structural organization of the studied indicators depending on the values of the indicators of righteousness, evil intent, and general humanism (spirituality) were determined by using the mathematical device of correlative analysis. Statistically important correlations of indicators were determined in all groups. For example, in the group of young females with the high level of humanism (spirituality), 93 statistically significant correlations were revealed; however, three indicators were not included in the correlative pleiad: "strive for domination", "weakness", and "honesty". The majority of correlations (13) in this group was determined by the factor of "anger expression". Despite the fact that the correlative group of indicators in the group of females with the medium humanism value was determined by the larger number of correlations than in the above group, the number of valid interdependencies at $p<0.001$ is lower in this sampling. The group of students with the low level of righteousness and humanism showed considerably lesser number of correlations between spiritual-moral and emotional-expressional characteristics. Totally, 39 statistically valid correlations were recorded, of which the number of correlation coefficients evidencing the close contingency of indicators is considerably less (there is only one correlation at the level of 0.66 , which corresponds to $\mathrm{p}<0.001$; and there are 11 of them at the level of $\mathrm{r}=0.55$, which corresponds to $\mathrm{p}<0.01$ ). At that, the following indicators were determined, which did not have significant correlations: the figurativeness of speech and the grammatical orientation of speech. The maximum number of correlations with emotional and expressional indicators in the group of females belongs to the indicator of "spiritual bluntness". The matrix of intercorrelations of the studied indicators of this sampling demonstrates a lesser functional unity of spiritual-moral and emotional-expressional singularities of personality. Thus, we can state that the structure of the studied indicators with females with high or medium level of spirituality is more integrated than the one of the group with the low level of humanism. A similar situation with intercorrelations is observed in the male groups. The closest correlative interdependencies and the largest number of them (69) was revealed in the group of males with high level of humanism. The correlative pleiad of indicators in this sampling is described with the high degree of correlation of both individual indicators of the spiritual-moral and emotional-expressional blocks and the listed blocks between each other. The indicators of voice tone and general expressiveness show the maximum number of correlations with the indicators of the spiritual and moral block. As distinct from the group described above, the pleiad of indicators with males who have a low level of humanism (spirituality) is created by a lesser number of correlations. Where the first group has nine valid interdependencies, the second group has only one (the difference in the named number of correlations is considerable: $p<0.001$ ); at the level of validity equal to $\mathrm{p}<0.01$, the number of correlations is equal to fifteen with males with the high level of humanism, and six - with the low level of given indicator.

\section{Discussion}

Thus the analysis of correlations of spiritual-moral and emotional-expressional singularities of students showed that there were statistically valid correlations between the indicators in all groups of the tested persons. Besides, the results of the analysis of correlations evidence the existence of rather close correlations of both spiritual-moral and emotional-expressional indicators between each other. However, these groups differ from each other by the nature and the number of the above-listed correlations. The groups with high level of humanism differ from the groups with low level of humanism by the fact that these groups are distinguished for their strong contingency of both spiritual-moral and emotional-expressional indicators between each other. In general, the determined correlations are confirmed in the works, which consider the emotional sphere of personality (Berkowitz, 1990; Charlesworth, 1974; Izard, 1965, 1989, 1990; Olshannikova, 1974; Rogers, 1961; Tomkins \& McCarter, 1964; Wessman \& Ricks, 1966), as well as in the researches of the spiritual and moral potential of personality (Abolin, 2002; Popov, 2000; Zinchenko, 1994; Znakov, 1998, etc.).

\section{Conclusion}

The study of the problem of spiritual and moral development of personality showed that this topic is urgent 
indeed both for development of psychological theories of personality and for practical implementation of parenting activities with respect to young personality, which has deviations of its spiritual and moral culture. Studies dedicated to the development of spiritual and moral aspects of the personality acknowledge the mechanisms of participation of emotional phenomena in assimilation of the spiritual and moral experience (Abolin, 2002; Anisimov, 2001; Izard \& Blumberg, 1985; Malatesta, 1990; Maslow, 1971; Zinchenko, 1994, etc.), which encouraged us to carry out an empirical research for a new vision of this aspect of the problem. The research dealt with the concepts of spirituality and morality of a human and principles and conditions of development of spiritual and moral personality. The results of theoretical researches were generalized, and the aspiration to determine the contemporary approach to the said problem was implemented.

Taking into account the main directions of the research, we managed to come to the following conclusions:

Theoretical analysis showed that spiritual and moral development of personality is implemented through human's assimilation of ideal forms of spiritual and moral culture by means of psychological tools (transmitters).

Based on the analysis of the main regulatory functions of psychological tools, it was determined that emotional and expressional characteristics could play an important role in assimilation of the spiritual and moral culture, being both the form of its expression and the psychological tools of mastering this culture at the same time.

Comparative analysis of the results of the diagnostics of spiritual-moral and emotional-expressional characteristics of students revealed statistically valid differences in all groups of the tested persons.

Comparison of the obtained correlative pleiads describing the spiritual-moral and emotional-expressional level between all groups allowed identifying the following trend: the increase of the general level of humanism and other spiritual and moral indicators of the responders is accompanied by increasing importance and contingency of the correlation with the emotional and expressional indicators. To clarify, we can add that the highest spiritual and moral development of students is associated with the most versatile structure of parameters' correlations.

\section{Recommendations}

Research materials may be used in the practice of working with college/institute/university students. A set of techniques that identify the spiritual potential of young people, allows objectively and quickly diagnose the level of development of personal spiritual and moral qualities of students, and thus to develop a program of spiritual and moral development of young people.

\section{Acknowledgments}

The work is performed according to the Russian Government Program of Competitive Growth of Kazan Federal University.

\section{References}

Abolin, L. M., \& Valiakhmetov, K. K. (2002). Spiritual and Moral Development of Personality in Eventual Activity (p. 230). Kazan: Karpol.

Aminev, G. A. (1994). Synectics of Spirituality: Conventional and Non-Conventional Approaches (p. 159). Ufa: Russian Psychological Society.

Anisimov, S. F. (2001). About the Primary Value of the morality in the Structure of Human Spirituality. Herald of the Moscow University, Series 7, Philosophy, 1, 26-36.

Berkowitz, L. (1990). On the formation and regulation of anger and aggression: A cognitive-neoassonciationistic analysis. American Psychologist, 45(4), 494-503. http://dx.doi.org/10.1037/0003-066X.45.4.494

Bozhovich, L. I. (1977). The Concept of Cultural and Historical Development of Psyche and its Prospects. Voprosy Psychologii, 2, 29-39.

Charlesworth, W. R. (1974). General issues in the study of fear: Section IV. In M. Lewis, \& L. A. Rosenblum (Eds.), The Origins of Fear (pp. 254-258). New York: John Wiley.

Elkonin, D. B. (1989). Selected Psychological Works (p. 554). Moscow: Pedagogika.

Holt, R. R. (1970). On the interpersonal and intrapersonal consequences of expressing or not expressing anger. Journal of Consulting and Clinical Psychology, 35(1), 8-12. http://dx.doi.org/10.1037/h0029609

Izard, C. E. (1965). Personal growth through group experience. In S. S. Tomkins, \& C. E. Izard (Eds.), Affect, cognition and personality (pp. 200-241). New York: Springer.

Izard, C. E. (1989). The structure and functions of emotion: Implications of cognition, motivation and personality. In I. S. Cohen (Ed.), The G. Stanley Hall Lectures Series (pp. 35-73). Washington: American Psychological 
Association.

Izard, C. E. (1990). Facial expressions and the regulation of emotions. Journal of Personality and Social Psychology, 58(3), 487-496. http://dx.doi.org/10.1037/0022-3514.58.3.487

Izard, C. E., \& Blumberg, S. H. (1985). Emotion theory and the role of emotions in anxiety in children and adults. In A. H. Tuma, \& J. D. Maser (Eds.), Anxiety and the anxiety disorders (pp. 109-129). Hillsdale, NJ: Erlbaum.

Malatesta, C. Z. (1990). The role of emotions in the development and organization of personality. In Sotio emotional Development (pp. 1-56). Tompson R. Nebraska Symposium on Motivation.

Maslow, A. (1971). The father reaches of human nature (p. 407). New York: Viking.

Olshannikova, A. E., \& Rabinovich, L. A. (1974). The Experience of Studying Certain Individual Characteristics of Emotionality. Voprosy Psikhologii, 3, 65-73.

Popov, L. M., Kashin, A. P., \& Starshinova, T. A. (2000). Good and Evil in Human Psychology (p. 176). Kazan-Nizhnekamsk: The Publishing House of the Kazan University.

Rogers, C. R. (1961). On becoming a person (p. 420). Boston: Houghton Mifflin.

Salmina, N. G. (1988). A Sign and a Symbol in Education (p. 288). The Publishing House of the Moscow University.

Tomkins, S. S., \& McCarter, R. (1964). What and where are the primary affects? Some evidence for a theory. Perceptual and Motor Skills, 18, 119-158. http://dx.doi.org/10.2466/pms.1964.18.1.119

Vygotsky, L. S. (2005). Tool and Sign in the Psychology of a Child. In V. V. Davydov (Ed.), Pedagogical Psychology (p. 671). Moscow: AST Aprel.

Wessman, A. E., \& Ricks, D. F. (1966). Mood and personality (p. 317). New York: Rinehart \& Winston.

Zinchenko, V. P., \& Morgunov, E. B. (1994). The Developing Human: The Sketches of Russian Psychology (p. 304). Moscow: Trivola.

Znakov, V. V. (1998). Human Spirituality in the Mirror of Psychological Knowledge and Religiosity. Voprosy Psikhologii, 3, 104-115.

\section{Copyrights}

Copyright for this article is retained by the author(s), with first publication rights granted to the journal. This is an open-access article distributed under the terms and conditions of the Creative Commons Attribution license (http://creativecommons.org/licenses/by/3.0/). 